Check for updates

Cite this: Mater. Adv., 2021, 2,3752

Received 18th August 2020, Accepted 13th April 2021

DOI: $10.1039 / \mathrm{d} 0 \mathrm{ma00614a}$

rsc.li/materials-advances

\section{Coupling effects of thermodynamics in multiple ion co-precipitation for precursors towards a layered oxide cathode $\dagger$}

\author{
He Zhao, ${ }^{a}$ Qi Zhang, (DD ${ }^{b}$ Xuan-Wen Gao, ${ }^{\text {a }}$ Jian-Zhong Li, ${ }^{a}$ Hua-Kun Liu ${ }^{b}$ and \\ Wen-Bin Luo*ab
}

\begin{abstract}
The co-precipitation process is the most frequently employed method to realize the simultaneous stoichiometric crystallization of multiple ions. The precipitation of different elements under a driving force can directly and primarily determine the degree of homogeneity of the co-precipitation product. Unlike individual element crystallization, the multiple ion coexistence co-precipitation process is complicated and a coupling effect is involved, as the thermodynamic behaviour of certain elements is much superior to that of others. This coupling effect can dramatically influence the whole thermodynamic behaviour in the liquid solution. Therefore, in order to achieve a high-quality product or precursor with various elements in a homogeneous distribution, the co-precipitation process can be efficiently controlled and balanced by the coupling effect resulting from the addition of certain elements. In an environment where $\mathrm{Co}^{2+}, \mathrm{Ni}^{2+}$, and $\mathrm{Mn}^{2+}$ ions coexist, owing to the thermodynamic coupling effect, the superior high supersaturation of $\mathrm{Al}^{3+}$ and the more negative change in the Gibbs free energy $(\Delta G)$ can efficiently balance the whole crystallization reaction by realizing a consistent precipitation driving force among the various ions, accelerating the precipitation of $\mathrm{Ni}^{2+}$ and $\mathrm{Mn}^{2+}$ ions and inhibiting the precipitation of $\mathrm{CO}^{2+}$ ions. Meanwhile, based on the initial formation of the $\mathrm{Al}(\mathrm{OH})_{3}$ seed crystals in the solution, multiple ions in the solution can be adsorbed and thus grow on the surface of $\mathrm{Al}(\mathrm{OH})_{3}$ to completely precipitate. The obtained Li-rich cathode material has demonstrated excellent electrochemical performance which can be attributed to the high quality precursor $\left(0.54 \mathrm{MnCO}_{3}\right.$. $\left.0.13 \mathrm{NiCO}_{3} \cdot 0.125 \mathrm{CoCO}_{3} \cdot 0.005 \mathrm{Al}(\mathrm{OH})_{3}\right)$ with a homogeneous distribution of elements.
\end{abstract}

\section{Introduction}

The co-precipitation process is the most conventional and an excellent option when stoichiometric chemistry is involved and has several advantages, including good homogeneity, high purity, high yields of product, high economic efficiency, and a controllable particle size distribution. ${ }^{1-3}$ By changing different parameters such as the $\mathrm{pH}$ value, reaction temperature and time, and concentration of the initial solution and material, the required final product can be accurately optimized and achieved. ${ }^{4-7}$ Its industrial feasibility and advanced technique mean that this scalable process is commonly employed in the

\footnotetext{
${ }^{a}$ School of Metallurgy, Northeastern University, Shenyang 110000, China. E-mail: luowenbin@smm.neu.edu.cn

${ }^{b}$ Institute for Superconducting and Electronic Materials, University of Wollongong, Wollongong, NSW 2522, Australia. E-mail: wl368@uowmail.edu.au

$\dagger$ Electronic supplementary information (ESI) available: These might include comments relevant to but not central to the matter under discussion, limited experimental and spectral data, and crystallographic data. See DOI: 10.1039/ d0ma00614a
}

synthesis of functional materials in various fields. ${ }^{8-11}$ Particularly, in the field of commercial energy storage materials, owing to these inherent advantages, the co-precipitation process is widely utilized to manufacture precursors for final active materials, such as different types of, as well as stoichiometric, $\mathrm{LiNi}_{x} \mathrm{Co}_{y}$ $\mathrm{Mn}_{1-x-y} \mathrm{O}_{2}, \mathrm{LiNi}_{0.5} \mathrm{Mn}_{1.5} \mathrm{O}_{4}$, and $\mathrm{LiNi}_{x} \mathrm{Co}_{y} \mathrm{Al}_{1-x-y} \mathrm{O}_{2} \cdot{ }^{12-22}$ The basic theory of the co-precipitation process is based on aqueous solution thermodynamics, which is closely related to the stability of the substance in aqueous solution. This stability determines the crystallization reaction in the liquid phase and is closely related to the potential, $\mathrm{pH}$ value, solution composition and concentration, temperature, and pressure of each substance in the solution..$^{23-25}$ In addition, the particle size, morphology, and stoichiometry of the precipitated crystalline product can be further affected by a combination of factors, including the precipitation crystallization reaction between the ions in the liquid phase and the deposited crystalline material, the adsorption reaction, and the thermodynamic coupling between the multiple reactions. As the crystal grains gradually grow and new crystal nuclei continuously appear, the coexistence phenomenon causes a 
competition between the crystallization reaction and the adsorption reaction. ${ }^{26-29}$ Therefore, how to control the crystallization reaction and adsorption reaction at the same time becomes a key point of the aqueous solution reaction. Crystals form along with the change in the ion concentration in the aqueous solution to form a supersaturated solution. This process can be considered as a Gibbs free energy $(\Delta G)$ reduction process. Thermodynamic coupling will be accompanied by and occurs in an environment where multiple ions coexist. The composition of the Gibbs free energy changes $(\Delta G)$ can be influenced, for example, accelerated, if one or more of the components of the Gibbs free energy change $(\Delta G)$ is very superior to the others. ${ }^{24,30,31}$ Therefore, in this work, the Gibbs free energy change $(\Delta G)$ and coupling coefficient are explored, based on the thermodynamic coupling, ion synergy, and supersaturation. In order to achieve high quality precursors with various elements in a homogenous distribution for Li-rich cathode materials, aluminum (Al) ion doping was employed to control the co-precipitation process and balance the precipitate driving force to realize multiple ion crystallization reactions simultaneously.

\section{Results and discussion}

Thermodynamic coupling effects among $\mathrm{Mn}^{2+}, \mathrm{Ni}^{2+}$, and $\mathrm{Co}^{2+}$

In the precipitation process under constant temperature and pressure conditions, the crystallization process of $\mathrm{Mn}^{2+}, \mathrm{Ni}^{2+}$, and $\mathrm{Co}^{2+}$ can be regarded as a Gibbs free energy $(\Delta G)$ reduction process. As shown in Fig. 1, when $\mathrm{Mn}^{2+}, \mathrm{Ni}^{2+}$, and $\mathrm{Co}^{2+}$ are separately precipitated using $\mathrm{Na}_{2} \mathrm{CO}_{3}$, the following reactions occur, respectively:

$$
\begin{aligned}
\mathrm{Mn}^{2+}+\mathrm{CO}_{3}{ }^{2-} & =\mathrm{MnCO}_{3} \\
\mathrm{Co}^{2+}+\mathrm{CO}_{3}{ }^{2-} & =\mathrm{CoCO}_{3} \\
\mathrm{Ni}^{2+}+\mathrm{CO}_{3}{ }^{2-} & =\mathrm{NiCO}_{3}
\end{aligned}
$$

The corresponding thermodynamic behavior can be described using the Gibbs free energy $(\Delta G)$ and reaction temperature $(T)$. Taking $\mathrm{MnCO}_{3}$ as a separate precipitation process, for example, in the early stage of the precipitation reaction, the thermodynamic behavior can be calculated based on eqn (4)-(7):

$$
\begin{gathered}
\Delta G_{1}=\Delta G_{1}^{\theta}-R T \ln \left(a_{\mathrm{Mn}^{2+}} \cdot a_{\mathrm{CO}^{2-}}\right) \\
\Delta G_{1}=R T K_{\mathrm{MnCO} 3}-R T \ln \left(a_{\mathrm{Mn}^{2+}} \cdot a_{\mathrm{CO}^{2-}}\right) \\
\Delta G_{1}=R T \ln \frac{K_{\mathrm{MnCO}_{3}}}{a_{\mathrm{Mn}^{2+}} \cdot a_{\mathrm{Co}_{3}^{2-}}}=R T \ln \frac{1}{S_{1}}
\end{gathered}
$$
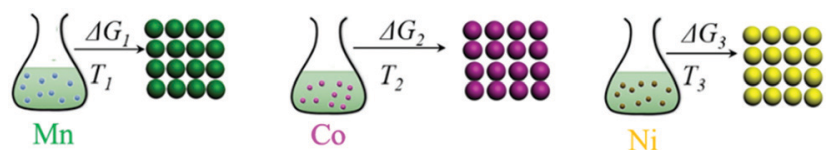

Fig. 1 Schematic illustration of the separate precipitation processes for $\mathrm{Mn}^{2+}, \mathrm{Ni}^{2+}$, and $\mathrm{Co}^{2+}$, and their corresponding thermodynamic parameters.
The supersaturation of manganese carbonate can be expressed as:

$$
S_{1}=\frac{a_{\mathrm{Mn}^{2+}} \cdot a_{\mathrm{CO}_{3}^{2-}}}{K_{\mathrm{MnCO}_{3}}}
$$

Similarly, for the corresponding processes for $\mathrm{CoCO}_{3}$ and $\mathrm{NiCO}_{3}$, the supersaturation and $\Delta G$ can be expressed as:

$$
\begin{gathered}
S_{2}=\frac{a_{\mathrm{Co}^{2+}} \cdot a_{\mathrm{CO}_{3}^{2-}}}{K_{\mathrm{CoCO}_{3}}} \\
\Delta G_{2}=R T \ln \frac{K_{\mathrm{CoCO}_{3}}}{a_{\mathrm{Co}^{2+}} \cdot a_{\mathrm{CO}_{3}^{2-}}}=R T \ln \frac{1}{S_{2}} \\
S_{3}=\frac{a_{\mathrm{Ni}^{2+}} \cdot a_{\mathrm{CO}_{3}^{2-}}}{K_{\mathrm{NiCO}_{3}}} \\
\Delta G_{3}=R T \ln \frac{K_{\mathrm{NiCO}_{3}}}{a_{\mathrm{Ni}^{2+}} \cdot a_{\mathrm{CO}_{3}{ }^{2-}}}=R T \ln \frac{1}{S_{3}}
\end{gathered}
$$

The separate precipitation parameters can be calculated and confirmed according to eqn (4)-(11) based on the data summarized in Tables S1-S3 in the ESI. $\dagger$ The corresponding values are listed as follows:

$$
\begin{gathered}
S_{1}=8633.3, \quad S_{2}=130142.9, \quad S_{3}=3.74 \\
\Delta G_{1}=-22466.5 \mathrm{~J} \mathrm{~mol}^{-1}, \quad \Delta G_{2}=-29191.5 \mathrm{~J} \mathrm{~mol}^{-1}, \\
\Delta G_{3}=-3269.8 \mathrm{~J} \mathrm{~mol}^{-1}
\end{gathered}
$$

A similar method was employed when the three elements were co-precipitated simultaneously. When $\mathrm{Mn}^{2+}, \mathrm{Ni}^{2+}$, and $\mathrm{Co}^{2+}$ are simultaneously precipitated using $\mathrm{Na}_{2} \mathrm{CO}_{3}$, the following reactions occur, respectively:

$$
\begin{gathered}
\mathrm{CO}_{3}^{2-}+x \mathrm{Mn}^{2+}+y \mathrm{Ni}^{2+}+(1-x-y) \mathrm{Co}^{2+}=x \mathrm{MnCO}_{3}+y \mathrm{NiCO}_{3} \\
+(1-x-y) \mathrm{CoCO}_{3}
\end{gathered}
$$

The thermodynamic behavior can be calculated based on eqn (12)-(17):

$$
\begin{gathered}
S_{4}=\frac{a_{\mathrm{Mn}^{2+}} \cdot a_{\mathrm{CO}_{3}^{2-}}}{K_{\mathrm{MnCO}_{3}}} \\
\Delta G_{4}=R T \ln \frac{K_{\mathrm{MnCO}_{3}}}{a_{\mathrm{Mn}^{2+}} \cdot a_{\mathrm{CO}_{3}^{2-}}}=R T \ln \frac{1}{S_{4}} \\
S_{5}=\frac{a_{\mathrm{Co}^{2+}} \cdot a_{\mathrm{CO}_{3}{ }^{2-}}}{K_{\mathrm{CoCO}_{3}}} \\
\Delta G_{5}=R T \ln \frac{K_{\mathrm{CoCO}_{3}}}{a_{\mathrm{Co}^{2+}} \cdot a_{\mathrm{CO}_{3}{ }^{2-}}}=R T \ln \frac{1}{S_{5}} \\
S_{6}=\frac{a_{\mathrm{Ni}^{2+}} \cdot a_{\mathrm{CO}_{3}{ }^{2-}}}{K_{\mathrm{NiCO}_{3}}} \\
\Delta G_{6}=R T \ln \frac{K_{\mathrm{NiCO}_{3}}}{a_{\mathrm{Ni}^{2+}} \cdot a_{\mathrm{CO}_{3}{ }^{2-}}}=R T \ln \frac{1}{S_{6}}
\end{gathered}
$$

The corresponding precipitation parameters can be calculated and confirmed according to eqn (12)-(17) based on the data 


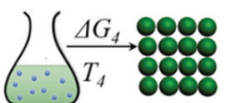

$\mathrm{Mn}$

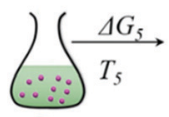

$\mathrm{Co}$

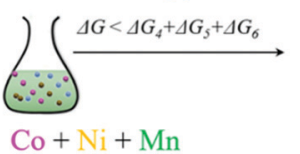

$\mathrm{Co}+\mathrm{Ni}+\mathrm{Mn}$

Fig. 2 Schematic illustration of the simultaneous co-precipitation processes for $\mathrm{Mn}^{2+}, \mathrm{Ni}^{2+}$, and $\mathrm{Co}^{2+}$, and the corresponding thermodynamic parameters

summarized in Table S4 (ESI $\dagger$ ). The corresponding values are listed as follows:

$$
\begin{gathered}
S_{4}=1.4 \times 10^{4}, \quad S_{5}=1.16 \times 10^{6}, \quad S_{6}=69 \\
\Delta G_{4}=-23664 \mathrm{~J} \mathrm{~mol}^{-1}, \quad \Delta G_{5}=-34614 \mathrm{~J} \mathrm{~mol}^{-1}, \\
\Delta G_{6}=-10496 \mathrm{~J} \mathrm{~mol}^{-1}
\end{gathered}
$$

In eqn (18), the ratio of $\mathrm{Mn}$ to $\mathrm{Ni}$ to $\mathrm{Co}$ is $3.97: 0.93: 1, x=0.673$, $y=0.158$ :

$$
\Delta G=x \Delta G_{4}+y \Delta G_{5}+(1-x-y) \Delta G_{6}=-23434 \mathrm{~J} \mathrm{~mol}^{-1}
$$

$\Delta G<0$ indicates that the crystallization reaction can be made spontaneous. Meanwhile, based on the summarized data and trend shown in Fig. 2, it can be concluded that the $\mathrm{CoCO}_{3}$ precipitation reaction driving force is much stronger than that of $\mathrm{MnCO}_{3}$, followed by $\mathrm{NiCO}_{3}$.

It is concluded that $\mathrm{CoCO}_{3}$ is most likely to precipitate during the co-precipitation reaction when multiple ions coexist, followed by $\mathrm{MnCO}_{3}$, and finally $\mathrm{NiCO}_{3}$. Meanwhile, compared with separate precipitation of the metal ions (Fig. 3), $\Delta G_{4}<$ $\Delta G_{1}, \Delta G_{5}<\Delta G_{2}, \Delta G_{6}<\Delta G_{3}$, it is concluded that the thermodynamic coupling effect exists when the three elements coprecipitate simultaneously. This coupling effect can accelerate the crystallization reaction to a certain extent.

\section{Thermodynamic coupling effects caused by $\mathrm{Al}^{3+}$ addition}

In a co-precipitation reaction system at constant temperature and pressure, the precursor product is $x \mathrm{MnCO}_{3} \cdot y \mathrm{NiCO}_{3}$.

(a)

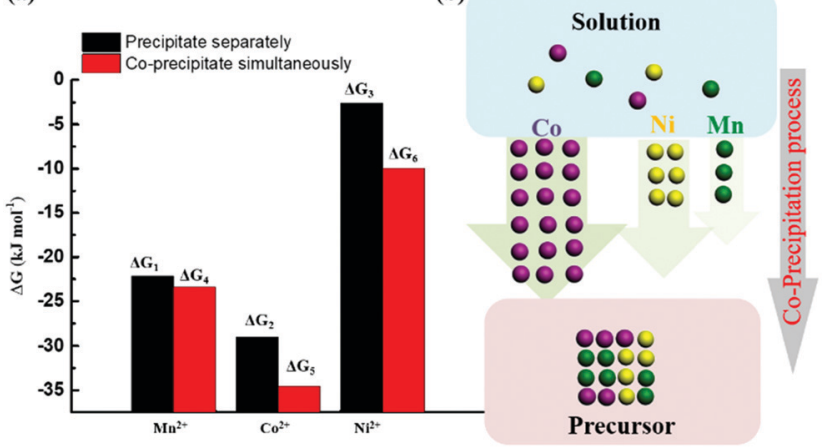

Fig. 3 (a) $\Delta G$ comparison between various elements precipitating separately and co-precipitating simultaneously; (b) schematic diagram of the simultaneous co-precipitation process for $\mathrm{Mn}^{2+}, \mathrm{Ni}^{2+}$, and $\mathrm{Co}^{2+}$. $z \mathrm{CoCO}_{3} \cdot(1-x-y-z) \mathrm{Al}_{2}\left(\mathrm{CO}_{3}\right)_{3}$, which is crystallized by $\mathrm{Na}_{2} \mathrm{CO}_{3}, \mathrm{MnSO}_{4}, \mathrm{NiSO}_{4}, \mathrm{CoSO}_{4}$, and $\mathrm{Al}_{2}\left(\mathrm{SO}_{4}\right)_{3}$. A case study of $1 \mathrm{M} x \mathrm{MnCO}_{3} \cdot y \mathrm{NiCO}_{3} \cdot z \mathrm{CoCO}_{3} \cdot(1-x-y-z) \mathrm{Al}_{2}\left(\mathrm{CO}_{3}\right)_{3}$ was produced and the reaction is as follows:

$$
\begin{aligned}
x \mathrm{Mn}^{2+} & +y \mathrm{Ni}^{2+}+z \mathrm{Co}^{2+}+(1-x-y-z) \mathrm{Al}^{3+}+\mathrm{CO}_{3}{ }^{2-}=x \mathrm{MnCO}_{3} \\
& +y \mathrm{NiCO}_{3}+z \mathrm{CoCO}_{3}+(1-x-y-z) / 2 \mathrm{Al}_{2}\left(\mathrm{CO}_{3}\right)_{3}
\end{aligned}
$$

Eqn (19) can be divided into the following individual precipitation reactions:

$$
\begin{gathered}
x \mathrm{Mn}^{2+}+x \mathrm{CO}_{3}{ }^{2-}=x \mathrm{MnCO}_{3} \\
y \mathrm{Ni}^{2+}+y \mathrm{CO}_{3}{ }^{2-}=y \mathrm{NiCO}_{3} \\
z \mathrm{Co}^{2+}+z \mathrm{CO}_{3}{ }^{2-}=z \mathrm{CoCO}_{3} \\
(1-x-y-z) \mathrm{Al}^{3+}+\frac{3(x-y-z)}{2} \mathrm{CO}_{3}{ }^{2-} \\
=\frac{(1-x-y-z)}{2} \mathrm{Al}_{2}\left(\mathrm{CO}_{3}\right)_{3}
\end{gathered}
$$

However, $\mathrm{Al}_{2}\left(\mathrm{CO}_{3}\right)_{3}$ cannot exist in water and tends to produce $\mathrm{Al}(\mathrm{OH})_{3}$ as in eqn (24). The solubility product constant is $3 \times 10^{-34}$.

$$
(1-x-y-z) \mathrm{Al}^{3+}+3 \mathrm{OH}^{-}=\mathrm{Al}(\mathrm{OH})_{3}
$$

As shown in Fig. 4, individual carbonates or hydroxides can be theoretically achieved. The corresponding thermodynamic behaviour can be described using the Gibbs free energy $(\Delta G)$ and reaction temperature $(T)$. Taking the $\mathrm{MnCO}_{3}$ precipitation process for example, in the early stage of the precipitation reaction, the thermodynamic behavior can be calculated based on eqn (25)-(28):

$$
\begin{gathered}
\Delta G_{7}=\Delta G_{7}^{\theta}-R T \ln \left(a_{\mathrm{Mn}}{ }^{2+} \cdot a_{\mathrm{CO}^{2-}}\right) \\
\Delta G_{7}=R T K_{\mathrm{MnCO} 3}-R T \ln \left(a_{\mathrm{Mn}^{2+}} \cdot a_{\mathrm{CO}^{2-}}\right) \\
\Delta G_{7}=R T \ln \frac{K_{\mathrm{MnCO}_{3}}}{a_{\mathrm{Mn}^{2+}} \cdot a_{\mathrm{CO}_{3}^{2-}}}=R T \ln \frac{1}{S_{7}}
\end{gathered}
$$

The supersaturation of manganese carbonate can be expressed as:

$$
S_{7}=\frac{a_{\mathrm{Mn}^{2+}} \cdot a_{\mathrm{CO}_{3}^{2-}}}{K_{\mathrm{MnCO}_{3}}}
$$

Similarly, for the corresponding processes for $\mathrm{CoCO}_{3}, \mathrm{NiCO}_{3}$, and $\mathrm{Al}(\mathrm{OH})_{3}$, the supersaturation and the Gibbs free energy can

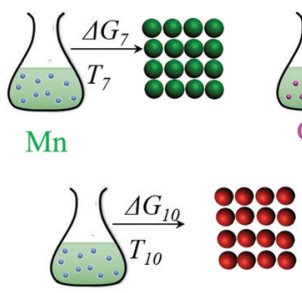

$\mathrm{Al}$

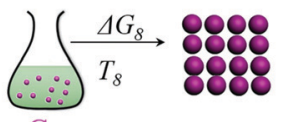

Co

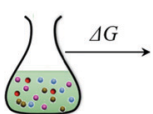

$\mathrm{Co}+\mathrm{Ni}+\mathrm{Mn}+\mathrm{Al}$

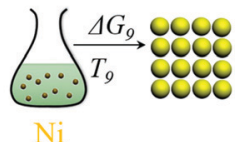

Fig. 4 Schematic illustration of the precipitation process and the corresponding thermodynamic parameters. 
be expressed as:

$$
\begin{aligned}
& S_{8}=\frac{a_{\mathrm{Co}^{2+}} \cdot a_{\mathrm{CO}_{3}^{2-}}}{K_{\mathrm{CoCO}_{3}}} \\
& \Delta G_{8}=R T \ln \frac{K_{\mathrm{CoCO}_{3}}}{a_{\mathrm{Co}^{2+}} \cdot a_{\mathrm{CO}_{3}^{2-}}}=R T \ln \frac{1}{S_{8}} \\
& S_{9}=\frac{a_{\mathrm{Ni}^{2+}} \cdot a_{\mathrm{CO}_{3}^{2-}}}{K_{\mathrm{NiCO}_{3}}} \\
& \Delta G_{9}=R T \ln \frac{K_{\mathrm{NiCO}_{3}}}{a_{\mathrm{Ni}^{2+}} \cdot a_{\mathrm{CO}_{3}{ }^{2-}}}=R T \ln \frac{1}{S_{9}} \\
& S_{10}=\frac{a_{\mathrm{Al}^{3+}} \cdot a_{\mathrm{OH}^{-}}}{K_{\mathrm{Al}(\mathrm{OH})_{3}}} \\
& \Delta G_{10}=R T \ln \frac{K_{\mathrm{Al}(\mathrm{OH})_{3}}}{a_{\mathrm{Al}^{3+}} \cdot a_{\mathrm{OH}^{-}}}=R T \ln \frac{1}{S_{10}}
\end{aligned}
$$

After chemical analysis and calculations, the concentrations of the various elements in the supernatant are summarized in Table S5 (ESI $\dagger$ ) after the co-precipitation reaction, with the Al content being increased from 0.0 to $0.0025,0.005$, and 0.0075 . The corresponding ion supersaturation $(S)$ and $\Delta G$ values of the reaction processes can be denoted as $S_{0}, S_{\mathrm{a}}, S_{\mathrm{b}}, S_{\mathrm{c}}$ and $\Delta G_{0}, \Delta G_{\mathrm{a}}$, $\Delta G_{\mathrm{b}}, \Delta G_{\mathrm{c}}$, respectively. All the data were calculated based on the above equations and are summarized in Tables S6 and S7 (ESI $\dagger$ ), and the changing trends are described as well in Fig. 5. As shown in Fig. 5(a and b), the $\mathrm{Al}^{3+}$ supersaturation increases first and then decreases while $\Delta G$ of $\mathrm{Al}^{3+}$ exhibits an opposite trend with $\mathrm{Al}^{3+}$ content from 0.0025 to 0.0075. Meanwhile, it is obvious that the supersaturation $(S)$ and $\Delta G$ values of $\mathrm{Mn}^{2+}$ and $\mathrm{Ni}^{2+}$ change dramatically when even a little amount of $\mathrm{Al}^{3+}$ was added. As shown in the schematic diagram for the precipitation process in Fig. 5c, owing to the (a)

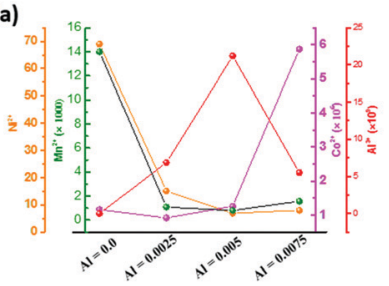

(c)

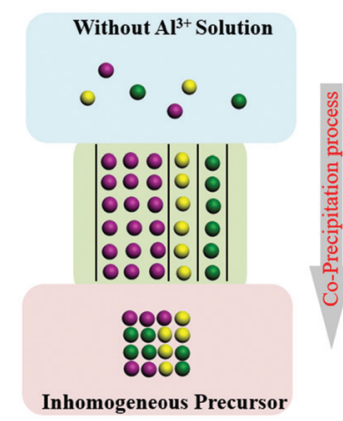

(b)
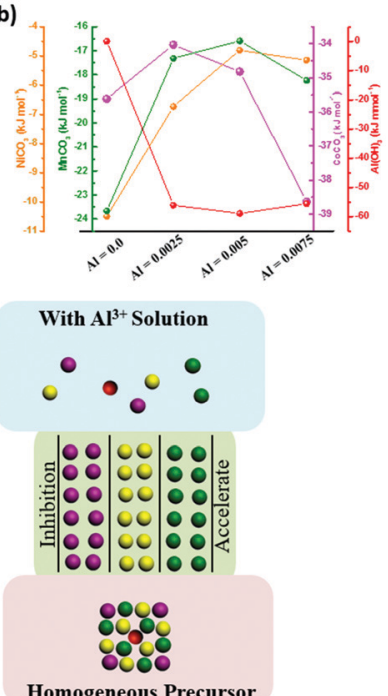

Fig. 5 ( $a$ and b) Trends in the supersaturation $(S)$ and Gibbs free energy $(\Delta G)$ change based on the addition of $\mathrm{Al}^{3+}$ ions; and (c) schematic illustration of the co-precipitation process with or without $\mathrm{Al}^{3+}$. thermodynamic coupling effect, the superior high supersaturation of $\mathrm{Al}^{3+}$ and the more negative $\Delta G$ represent the driving force to accelerate the precipitation of $\mathrm{Ni}^{2+}$ and $\mathrm{Mn}^{2+}$ ions. Meanwhile, due to the formation of the $\mathrm{Al}(\mathrm{OH})_{3}$ seed crystals and good adsorption capability in the solution, $\mathrm{Ni}^{2+}$ and $\mathrm{Mn}^{2+}$ ions in the solution can be adsorbed and thus grow on the surfaces of $\mathrm{Al}(\mathrm{OH})_{3}$ to completely precipitate. On the other hand, the $\mathrm{Co}^{2+}$ precipitation behavior is opposite to that of $\mathrm{Ni}^{2+}$ and $\mathrm{Mn}^{2+}$ ions. When the $\mathrm{Al}^{3+}$ addition is 0.005 , the thermodynamic behavior of the various elements reaches a relatively consistent degree so as to co-precipitate simultaneously. Therefore, it can be concluded that $\mathrm{Al}^{3+}$ doping, even a little amount, can dramatically affect the precipitation of $\mathrm{Ni}^{2+}, \mathrm{Mn}^{2+}$, and $\mathrm{Co}^{2+}$ ions. By means of the thermodynamic coupling effect resulting from $\mathrm{Al}^{3+}$ addition, the precipitation consistency of different elements can be balanced and achieved by acceleration or inhibition.

The compound produced by the four kinds metal ions crystallization reaction of four kinds of metal ions is $x \mathrm{MnCO}_{3} \cdot y \mathrm{NiCO}_{3} \cdot z \mathrm{CoCO}_{3} \cdot(1-x-y-z) \mathrm{Al}(\mathrm{OH})_{3} \cdot \Delta G$ for this reaction can be expressed as:

$$
\Delta G=x \Delta G_{7}+y \Delta G_{8}+z \Delta G_{9}+(1-x-y-z) \Delta G_{10}
$$

When the $\mathrm{Al}$ content is 0 , and the corresponding $x=0.673$, $y=0.158$, and $z=0.169$, the result is:

$$
\Delta G_{0}=-23434.0 \mathrm{~J} \mathrm{~mol}^{-1}
$$

When the $\mathrm{Al}$ content is 0.0025 , and the corresponding $x=0.6675, y=0.1686$, and $z=0.1635$, it follows that:

$$
\Delta G_{\mathrm{a}}=-18269.6 \mathrm{~J} \mathrm{~mol}^{-1}
$$

When the $\mathrm{Al}$ content is 0.005 , and the corresponding $x=0.6638$, $y=0.1693$, and $z=0.1660$, it follows that:

$$
\Delta G_{\mathrm{b}}=-17658.1 \mathrm{~J} \mathrm{~mol}^{-1}
$$

When the $\mathrm{Al}$ content is 0.0075 , and the corresponding $x=0.6670, y=0.1693$, and $z=0.1625$, it follows that:

$$
\Delta G_{\mathrm{c}}=-19380.2 \mathrm{~J} \mathrm{~mol}^{-1} \text {. }
$$

With the order is $\Delta G_{0}<\Delta G_{\mathrm{c}}<\Delta G_{\mathrm{a}}<\Delta G_{\mathrm{b}}<0$, it can be concluded that $\mathrm{Al}^{3+}$ accelerates the whole co-precipitation reaction to a certain extent, and the acceleratory effect is relatively large when the aluminum content is 0.005 . With increasing $\mathrm{Al}$ content, however, the precipitation of $\mathrm{Mn}^{2+}$ and $\mathrm{Ni}^{2+}$ can be slightly enhanced, and it can enhance the $\mathrm{Co}^{2+}$ precipitation as well until aluminium content reaches 0.005 . The element distribution can be investigated by field emission scanning electron microscopy assisted by energy dispersive spectroscopy (FESEM-EDS), as shown in Fig. S1 and S2 (ESI $\dagger$ ). As with the results of thermodynamic calculations, $\mathrm{Al}^{3+}$ ion addition can dramatically influence the distribution of the various elements in the precursors. By optimizing the amount of $\mathrm{Al}^{3+}$ addition, the degree of homogeneity of the element distribution changes as well. When the $\mathrm{Al}^{3+}$ ion addition increases from 0 to 0.005 , the distribution of the different 

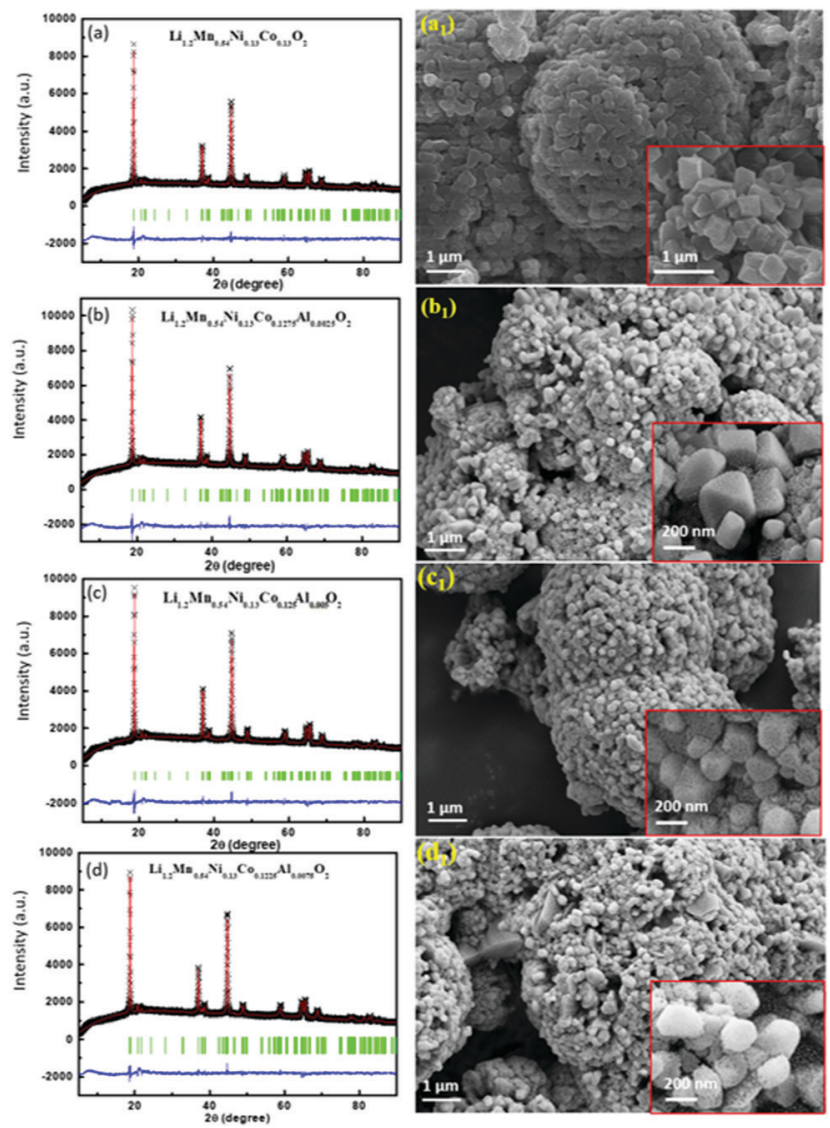

Fig. 6 XRD patterns with refinements (left, black symbols are the experimental data, the red line is the fitted curve, the green vertical lines are the standard lines, and the blue line is the difference spectrum), and FESEM images (right), with the corresponding enlargements in the insets, of $\mathrm{Li}\left[\mathrm{Li}_{0.2} \mathrm{Mn}_{0.54} \mathrm{Ni}_{0.13} \mathrm{Co}_{0.13-x} \mathrm{Al}_{x} \mathrm{O}_{2}\right.$ with different amounts of $\mathrm{Al}$ element: 0 (a) to 0.0025 (b), 0.005 (c), and 0.0075 (d).

elements shows a positive trend, while it becomes negative when the $\mathrm{Al}^{3+}$ ion addition content reaches as high as 0.0075 .

The Li-rich cathode materials were synthesized using the conventional high temperature annealing process from the prepared precursors and stoichiometric $\mathrm{Li}_{2} \mathrm{CO}_{3}$. As shown in the X-ray diffraction (XRD) patterns in Fig. 6, all the final $\mathrm{Li}\left[\mathrm{Li}_{0.2} \mathrm{Mn}_{0.54} \mathrm{Ni}_{0.13} \mathrm{Co}_{0.13-x} \mathrm{Al}_{x}\right] \mathrm{O}_{2}(x=0,0.0025,0.005,0.0075)$ samples show similar patterns. The phase of the products is assigned to the $\alpha-\mathrm{NaFeO}_{2}$ layered structure with the rhombohedral $R \overline{3} m$ space group and a $\mathrm{Li}_{2} \mathrm{MnO}_{3}$-like layered structure with the $C 2 / M$ space group. ${ }^{13,32-35}$ No diffraction peaks from impurity phases are observed. The Rietveld refinements were based on the XRD patterns. The observed patterns are in good agreement with the calculated pattern, and the parameters $R_{\mathrm{p}}$, $R_{\mathrm{wp}}$, and $\chi^{2}$, where $R_{\mathrm{p}}$ and $R_{\mathrm{wp}}$ are the profile and weighted profile $R$-factors, and $\chi^{2}$ is the goodness-of-fit parameter, are, respectively, $2.82 \%, 1.75 \%$, and $2.35 \%$, which indicate the satisfactory quality of the Rietveld refinement. The lattice parameters of the sample were calculated and are summarized in Table S8 (ESI $\dagger$ ). The morphologies of the samples were examined, and the corresponding FESEM images are shown in Fig. 6 and Fig. S3 $(\mathrm{ESI} \dagger)$ as well. The secondary particles, aggregated from a large amount of primary crystals, have sizes in the range of 5-10 $\mu \mathrm{m}$. In the case of pure sample $\mathrm{Li}\left[\mathrm{Li}_{0.2} \mathrm{Mn}_{0.54} \mathrm{Ni}_{0.13} \mathrm{Co}_{0.13}\right] \mathrm{O}_{2}$, the primary crystals show a regular octahedral structure with sharp edges and corners. The surface of the primary crystal is smooth and intact as well. There is an obvious change, however, once $\mathrm{Al}^{3+}$ ions are added. The sharpness of the octahedral structure becomes weaker with rounded edges and corners. Meanwhile, there is a large number of pores on the surfaces of the primary crystals. For cathode materials for lithium ion batteries, this structure has inherent advantages for electrolyte penetration, which can accelerate the reaction kinetics as well.

To analyse the surface structure at the atomic scale, high angle annular dark field-scanning transmission electron microscopy (HAADF-STEM) images were employed, as shown in Fig. 7 and Fig. S4 (ESI $\dagger$ ). According to the selected area electron diffraction (SAED) patterns in Fig. 7(a and b) and Fig. S3 (ESI $\dagger$ ), it is obvious that the $\mathrm{Li}\left[\mathrm{Li}_{0.2} \mathrm{Mn}_{0.54} \mathrm{Ni}_{0.13}\right.$ $\left.\mathrm{Co}_{0.13-x} \mathrm{Al}_{x}\right] \mathrm{O}_{2}$ samples show two-phase combination diffraction patterns, which is consistent with the XRD results as well. ${ }^{36}$ Meanwhile, the distribution of elements in the primary crystals was characterized by high-angle annular dark-field STEM-EDS (HAADF-STEM-EDS) as shown in Fig. 7(e-i) and Fig. S5 (ESI $\dagger$ ). All the elements show a similar homogeneous distribution over the entire area.

The electrochemical performance was investigated on various samples of $\mathrm{Li}_{1.2} \mathrm{Mn}_{0.54} \mathrm{Co}_{0.13-x} \mathrm{Ni}_{0.13} \mathrm{Al}_{x} \mathrm{O}_{2} \quad(x=0$, $0.0025,0.005$, and 0.0075). As shown in Fig. 8(a and b) in the cyclic voltammograms (CVs) in the voltage range of $2.0-4.8 \mathrm{~V}$ at

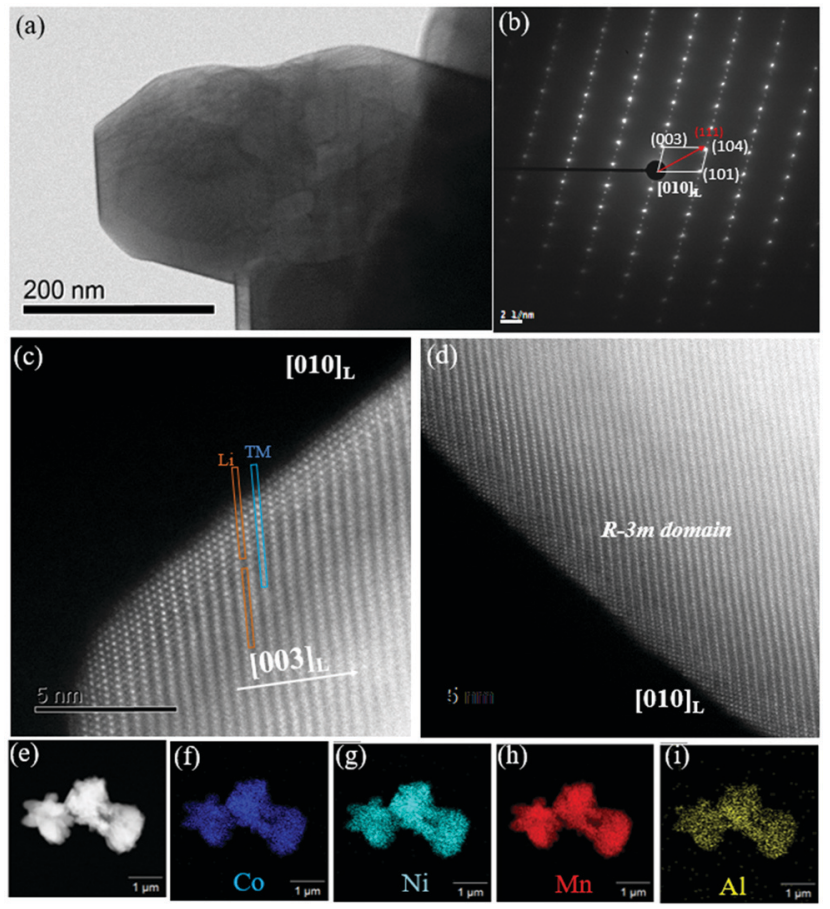

Fig. 7 (a) STEM image of $\mathrm{Li}\left[\mathrm{Li}_{0.2} \mathrm{Mn}_{0.54} \mathrm{Ni}_{0.13} \mathrm{Co}_{0.13-x} \mathrm{Al}_{x}\right] \mathrm{O}_{2}$; (b) the corresponding selected area electron diffraction pattern (SAED); ( $c$ and $d$ ) the surface structure at the atomic scale in HAADF-STEM images; and (e-i) distributions of various elements. 

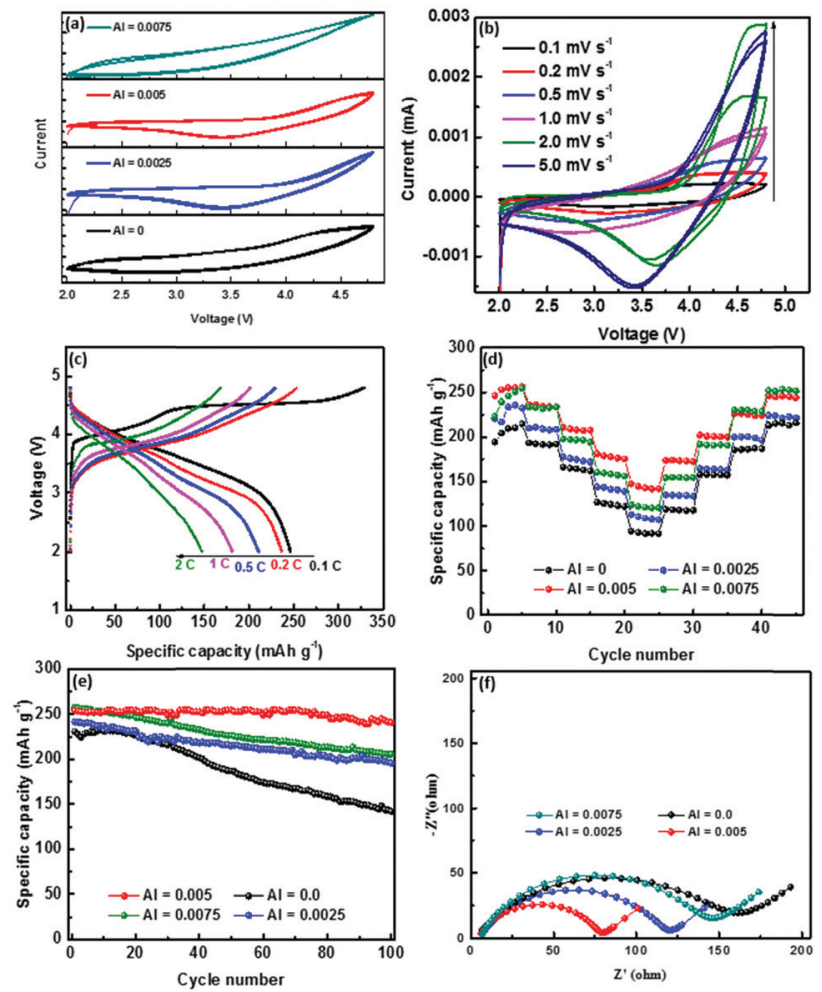

Fig. 8 (a) $\mathrm{CV}$ patterns of $\mathrm{Li}_{1.2} \mathrm{Mn}_{0.54} \mathrm{Co}_{0.13-x} \mathrm{Ni}_{0.13} \mathrm{Al}_{x} \mathrm{O}_{2}(x=0,0.0025$ 0.005 , and 0.0075 ) at $5.0 \mathrm{mV} \mathrm{s}^{-1}$; (b) $\mathrm{CV}$ patterns of $\mathrm{Li}_{1.2} \mathrm{Mn}_{0.54} \mathrm{Co}_{0.125}$ $\mathrm{Ni}_{0.13} \mathrm{Al}_{0.005} \mathrm{O}_{2}$ from $0.1 \mathrm{mV} \mathrm{s}^{-1}$ to $5.0 \mathrm{mV} \mathrm{s}^{-1}$; (c) charge and discharge curves of $\mathrm{Li}_{1.2} \mathrm{Mn}_{0.54} \mathrm{CO}_{0.125} \mathrm{Ni}_{0.13} \mathrm{Al}_{0.005} \mathrm{O}_{2}$ from $0.1 \mathrm{C}$ to $2 \mathrm{C}$; (d) rate performance; (e) cycling performance; and (f) EIS spectra of $\mathrm{Li}_{1.2} \mathrm{Mn}_{0.54}$ $\mathrm{Co}_{0.13-x} \mathrm{Ni}_{0.13} \mathrm{Al}_{x} \mathrm{O}_{2}(x=0,0.0025,0.005$, and 0.0075$)$.

various scanning rates, all the samples present the standard lithium-rich cathode pattern. ${ }^{37}$ Compared with pure $\mathrm{Li}_{1.2} \mathrm{Mn}_{0.54} \mathrm{Co}_{0.13} \mathrm{Ni}_{0.13} \mathrm{O}_{2}$ and $\mathrm{Li}_{1.2} \mathrm{Mn}_{0.54} \mathrm{Co}_{0.1225} \mathrm{Ni}_{0.13} \mathrm{Al}_{0.075} \mathrm{O}_{2}$, $\mathrm{Li}_{1.2} \mathrm{Mn}_{0.54} \mathrm{Co}_{0.1275} \mathrm{Ni}_{0.13} \mathrm{Al}_{0.0025} \mathrm{O}_{2}$ and $\mathrm{Li}_{1.2} \mathrm{Mn}_{0.54} \mathrm{Co}_{0.125}$ $\mathrm{Ni}_{0.13} \mathrm{Al}_{0.005} \mathrm{O}_{2}$ show a positive lithiation peak corresponding to a high discharge potential. Fig. $8 \mathrm{c}$ shows the initial charge and discharge curves of $\mathrm{Li}_{1.2} \mathrm{Mn}_{0.54} \mathrm{Co}_{0.125} \mathrm{Ni}_{0.13} \mathrm{Al}_{0.005} \mathrm{O}_{2}$ at different rates over the voltage range of 2.0-4.8 V. They have typical flat voltage plateaus at around $4.5 \mathrm{~V}$, which may be attributed to the two-phase reaction of $\mathrm{Li}_{1.2} \mathrm{Mn}_{0.54} \mathrm{Co}_{0.125}$ $\mathrm{Ni}_{0.13} \mathrm{Al}_{0.005} \mathrm{O}_{2}$. The $\mathrm{Li}_{1.2} \mathrm{Mn}_{0.54} \mathrm{Co}_{0.125} \mathrm{Ni}_{0.13} \mathrm{Al}_{0.005} \mathrm{O}_{2}$ sample exhibited discharge capacities of 246.7, 236.6, 210.4, 181.6, and $148.1 \mathrm{~mA} \mathrm{~h} \mathrm{~g}^{-1}$ at $0.1 \mathrm{C}, 0.2 \mathrm{C}, 0.5 \mathrm{C}, 1.0 \mathrm{C}$, and $2.0 \mathrm{C}$, respectively. The results demonstrate that $\mathrm{Al}^{3+}$ doping has a significant effect on the discharge capacities of $\mathrm{Li}_{1.2} \mathrm{Mn}_{0.54}$ $\mathrm{Co}_{0.13-x} \mathrm{Ni}_{0.13} \mathrm{Al}_{x} \mathrm{O}_{2}$ at different current rates. This is because the $\mathrm{Al}$ element induces changes in the properties of the $\mathrm{Li}_{1.2} \mathrm{Mn}_{0.54} \mathrm{Co}_{0.125} \mathrm{Ni}_{0.13} \mathrm{Al}_{0.005} \mathrm{O}_{2}$ samples with homogeneous element distributions without impurity phases, which cause more reactions and a shorter distance for fast Li-ion diffusion in the redox reaction process. Fig. 8e and Fig. S6 (ESI $\dagger$ ) show the cycling performance of pristine $\mathrm{Li}_{1.2} \mathrm{Mn}_{0.54}$ $\mathrm{Co}_{0.13-x} \mathrm{Ni}_{0.13} \mathrm{Al}_{x} \mathrm{O}_{2}$ ( $x=0,0.0025,0.005$, and 0.0075). Compared with the pure samples, the $\mathrm{Al}$ doped materials presented a clearly steady cycling property. The electrochemical impedance spectra of pristine $\mathrm{Li}_{1.2} \mathrm{Mn}_{0.54} \mathrm{Co}_{0.13} \mathrm{Ni}_{0.13} \mathrm{O}_{2}$ and $\mathrm{Li}_{1.2} \mathrm{Mn}_{0.54}$ $\mathrm{Co}_{0.13-x} \mathrm{Ni}_{0.13} \mathrm{Al}_{x} \mathrm{O}_{2}(x=0,0.0025,0.005$ and 0.0075$)$ are shown in Fig. 8f. The impedance spectra with different amounts of $\mathrm{Al}$ doping consist of capacitive loops at high frequency and a straight line at low frequency. Impedance values calculated from the equivalent circuits are shown in Table S9 (ESI $\dagger$ ). This shows that the Al doping samples exhibit an obvious improvement in the mobility of $\mathrm{Li}^{+}$diffusion. In general, $\mathrm{Al}$ doping has a positive influence on electronic conductivity and the change of the lattice structure in the layered lithium cathode material. As shown by the change of the charge transfer resistance value, the electronic conductivity activation energy of the material is lower. The improvement of electronic conductivity contributes to the better electrochemical performance of the lithium-rich cathode material.

\section{Conclusion}

Based on the thermodynamic calculations, it can be concluded that a coupling effect occurs when multiple ions co-exist in the liquid solution and under a simultaneous crystallization reaction. Although there are different driving forces towards precipitation of the various elements, owing to the super-high supersaturation and the more negative $\Delta G$ resulting from a small amount of $\mathrm{Al}^{3+}$ addition, the coupling effects can efficiently control and balance the co-precipitation process, accelerating the precipitation of $\mathrm{Ni}^{2+}$ and $\mathrm{Mn}^{2+}$ ions and inhibiting the precipitation of $\mathrm{Co}^{2+}$ ions. Meanwhile, based on the formation of the $\mathrm{Al}(\mathrm{OH})_{3}$ seed crystals in the solution, multiple ions in the solution can adsorb and grow on the surfaces of $\mathrm{Al}(\mathrm{OH})_{3}$ to completely precipitate. When $\mathrm{Al}^{3+}$ addition is 0.005 , the obtained $\left(0.54 \mathrm{MnCO}_{3} \cdot 0.13 \mathrm{NiCO}_{3} \cdot 0.125 \mathrm{CoCO}_{3}\right.$. $\left.0.005 \mathrm{Al}(\mathrm{OH})_{3}\right)$ precursor has a good homogenous element distribution, which paves the way for the further high electrochemical performance of the Li-rich cathode material.

\section{Experimental section}

\section{Synthesis of precursors and $\mathrm{Li}_{1.2} \mathrm{Mn}_{0.54} \mathrm{Ni}_{0.13} \mathrm{Co}_{0.13-x} \mathrm{Al}_{x} \mathrm{O}_{2}$}

Various precursors were synthesized by a co-precipitation process. Stoichiometric amounts of $\mathrm{NiSO}_{4} \cdot 6 \mathrm{H}_{2} \mathrm{O}(>99 \%), \mathrm{CoSO}_{4} \cdot 7 \mathrm{H}_{2} \mathrm{O}$ (>99\%), $\mathrm{MnSO}_{4} \cdot \mathrm{H}_{2} \mathrm{O}(>99 \%)$, and $\mathrm{Al}_{2}\left(\mathrm{SO}_{4}\right)_{3}(>99 \%)$ were uniformly mixed and dissolved into deionized water. This mixed metal solution was pumped into a continuously stirred tank reactor. At the same time, $\mathrm{Na}_{2} \mathrm{CO}_{3}$ solution as a precipitant and an appropriate amount of $\mathrm{NH}_{4} \mathrm{OH}$ solution as a $\mathrm{pH}$ control agent were also separately fed into the reactor in ambient air. The temperature, $\mathrm{pH}$, and stirring speed of the mixed solution were carefully controlled throughout the entire co-precipitation process. Then, the resultant powders were filtered, washed, and dried at $120{ }^{\circ} \mathrm{C}$ in air. Finally, the obtained carbonate precursor was thoroughly mixed with the required $\mathrm{Li}_{2} \mathrm{CO}_{3}$ and calcined at $850{ }^{\circ} \mathrm{C}$ for $10 \mathrm{~h}$ in air. An excess of $5 \mathrm{~mol} \% \mathrm{Li}_{2} \mathrm{CO}_{3}$ was used to compensate for the volatilization of $\mathrm{Li}$ during calcination. 


\section{Materials characterization}

$\mathrm{XRD}$ measurements were performed to investigate the crystal structure using a PLXcel 3D X-ray diffractometer with a nonmonochromated $\mathrm{Cu} \mathrm{K} \alpha \mathrm{X}$-ray source. Crystallographic structure analysis by the Rietveld method was carried out using the Fullprof Suite program. The morphology of the samples was examined using field emission scanning electron microscopy (FE-SEM; JEOL JSM-7500). Transmission electron microscopy (TEM) investigations were performed using a $200 \mathrm{kV}$ JEOL 2011 instrument. Scanning transmission electron microscopy (STEM), EELS, and EDS were performed using a $200 \mathrm{kV} \mathrm{JEOL}$ 2011 instrument.

\section{Electrochemical performance measurement}

The electrochemical properties were evaluated by using R2032type coin cells assembled in an argon-filled glove box. Positive electrodes were prepared by mixing $80 \mathrm{wt} \%$ active materials, $10 \mathrm{wt} \%$ acetylene black, and $10 \mathrm{wt} \%$ polyvinylidene fluoride (PVDF) in $N$-methyl-2-pyrrolidone and coating the slurry on $\mathrm{Al}$ foil. The electrodes were dried at $110{ }^{\circ} \mathrm{C}$ in vacuum. The mass loading of the electrodes was in the range of 1.2 to $1.5 \mathrm{mg} \mathrm{cm}^{-2}$. The electrolyte was $1 \mathrm{M} \mathrm{LiPF}_{6}$ dissolved in ethylene carbonate (EC)/dimethyl carbonate (DMC) (volume ratio 1:1). Li metal was used as the negative electrodes for the half-cells. Celgard 2320 membrane was used as the separator. Galvanostatic charge/discharge tests were performed using a LAND multichannel battery testing system (CT2001A, Wuhan Jinnuo Electronics Co., Ltd). CV curves were acquired with an electrochemical workstation (Bio-logic EC Lab VMP3).

\section{Conflicts of interest}

There are no conflicts to declare.

\section{Acknowledgements}

H. Zhao and Q. Zhang made equal contribution to this work. This work was supported by the Fundamental Research Funds for the Central Universities (N2025018) (N2025009), the National Natural Science Foundation of China (No. 51374053), the Iron and Steel Joint Research Fund of the National Natural Science Foundation and China Baowu Steel Group Corporation Limited (No. U1760118). The authors would like to also thank Dr Tania Silver for critical reading of the manuscript, and also acknowledge the use of the facilities in the UOW Electron Microscopy Center, with particular thanks to Dr Gilberto Casillas-Garcia. The manuscript was written through the contributions of all authors. All authors have given approval to the final version of the manuscript.

\section{Notes and references}

1 Y.-K. Sun, Z. Chen, H.-J. Noh, D.-J. Lee, H.-G. Jung, Y. Ren, S. Wang, C. S. Yoon, S. T. Myung and K. Amine, Nat. Mater., 2012, 11, 942.
2 C. Liu, F. Li, L. P. Ma and H. M. Cheng, Adv. Mater., 2010, 22, E28-E62.

3 J. Deng, W. B. Luo, X. Lu, Q. Yao, Z. Wang, H. K. Liu, H. Zhou and S.-X. Dou, Adv. Energy Mater., 2018, 8, 1701610.

4 W. Li, X. Liu, H. Celio, P. Smith, A. Dolocan, M. Chi and A. Manthiram, Adv. Energy Mater., 2018, 8, 1703154.

5 J. Zhang, Z. Yang, R. Gao, L. Gu, Z. Hu and X. Liu, ACS Appl. Mater. Interfaces, 2017, 9, 29794-29803.

6 A. Boulineau, L. Simonin, J. F. Colin, E. Canévet, L. Daniel and S. Patoux, Chem. Mater., 2012, 24, 3558-3566.

7 J. Zheng, S. Myeong, W. Cho, P. Yan, J. Xiao, C. Wang, J. Cho and J. G. Zhang, Adv. Energy Mater., 2017, 7, 1601284.

8 E. A. Olivetti, G. Ceder, G. G. Gaustad and X. Fu, Joule, 2017, 1, 229-243.

9 J. Deng, W. B. Luo, S. L. Chou, H. K. Liu and S.-X. Dou, Adv. Energy Mater., 2018, 8, 1701428.

10 P. Hou, H. Zhang, Z. Zi, L. Zhang and X. Xu, J. Mater. Chem. A, 2017, 5, 4254-4279.

11 M. H. Lee, Y. J. Kang, S. T. Myung and Y. K. Sun, Electrochem. Acta, 2004, 50, 939-948.

12 X. Zeng, C. Zhan, J. Lu and K. Amine, Chem, 2018, 4, 690-704. 13 R. Malik, Joule, 2017, 1, 647-648.

14 J. L. Shi, D. D. Xiao, M. Ge, X. Yu, Y. Chu, X. Huang, X. D. Zhang, Y. X. Yin, X. Q. Yang, Y. G. Guo, L. Gu and L. L. J. Wan, Adv. Mater., 2018, 30, 1705575.

15 H. H. Ryu, K. J. Park, C. S. Yoon and Y. K. Sun, Chem. Mater., 2018, 30, 1155-1163.

16 H. H. Sun and A. Manthiram, Chem. Mater., 2017, 29, 8486-8493.

17 C. S. Yoon, K. J. Park, U. H. Kim, K. H. Kang, H. H. Ryu and Y. K. Sun, Chem. Mater., 2017, 29, 10436-10445.

18 W. Yan, Y. Xie, J. Jiang, D. Sun, X. Ma, Z. Lan and Y. Jin, ACS Sustainable Chem. Eng., 2018, 6, 4625-4632.

19 M. D. Radin, J. Alvarado, Y. S. Meng and A. VanderVen, Nano Lett., 2017, 17, 7789-7795.

20 X. H. Zhang, W. L. Pang, F. Wan, J. Z. Guo, H. Y. Lü, J. Y. Li, Y. M. Xing, J. P. Zhang and X. L. Wu, ACS Appl. Mater. Interfaces, 2016, 8, 20650-20659.

21 W. L. Pang, X. H. Zhang, J. Z. Guo, J. Y. Li, X. Yan, B. H. Hou, H. Y. Guan and X. L. Wu, J. Power Sources, 2017, 356, 80-88.

22 M. Eilers-Rethwisch, M. Winter and F. M. Schappacher, J. Power Sources, 2018, 387, 101-107.

23 K. Henzler, E. O. Fetisov, M. Galib, M. D. Baer, B. A. Legg, C. Borca, J. M. Xto, S. Pin, J. L. Fulton, G. K. Schenter, N. Govind, J. I. Siepmann, C. J. Mundy, T. Huthwelker and J. J. DeYoreo, Sci. Adv., 2018, 4, 6283.

24 C. Schwarze, A. Gupta, T. Hickel and R. Darvishi Kamachali, Phys. Rev. B, 2017, 95, 174101.

25 A. Carino, A. Testino, M. R. Andalibi, F. Pilger, P. Bowen and C. Ludwig, Cryst. Growth Des., 2017, 17, 2006-2015.

26 G. Wang, Y. Liu, C. Gao, L. Guo, M. Chi, K. Ijiro, M. Maeda and Y. Yin, Chem, 2017, 3, 678-690.

27 A. Naillon, P. Joseph and M. Prat, J. Cryst. Growth, 2017, 463, 201-210.

28 S. Al-Jibbouri and J. Ulrich, Cryst. Res. Technol, 2001, 36, 1365-1375.

29 F. Fu, Q. Wang, Y. P. Deng, C. H. Shen, X. X. Peng, L. Huang and S. G. Sun, J. Mater. Chem. A, 2015, 3, 5197-5203. 
30 H. Chen, P. Feng, S. Ye and W. Sun, Constr. Build. Mater., 2018, 185, 391-401.

31 S. Shu, P. B. Wells, N. Almirall, G. R. Odette and D. D. Morgan, Acta Mater., 2018, 157, 298-306.

32 W. H. Kan, B. Deng, Y. Xu, A. K. Shukla, T. Bo, S. Zhang, J. Liu, P. Pianetta, B. T. Wang, Y. Liu and G. Chen, Chem, 2018, 4(9), 2108-2123.

33 Y. Zuo, B. Li, N. Jiang, W. Chu, H. Zhang, R. Zou and D. Xia, Adv. Mater., 2018, 30, 1707255.
34 J. An, L. Shi, G. Chen, M. Li, H. Liu, S. Yuan, S. Chen and D. Zhang, J. Mater. Chem. A, 2017, 5, 19738-19744.

35 S. Kim, W. Cho, X. Zhang, Y. Oshima and J. W. Choi, Nat. Commun., 2016, 7, 13598.

36 Y. Zhao, J. Liu, S. Wang, R. Ji, Q. Xia, Z. Ding, W. Wei, Y. Liu, P. Wang and D. G. Ivey, Adv. Funct. Mater., 2016, 26, 4760-4767.

37 X. Yu, Y. Lyu, L. Gu, H. Wu, S. M. Bak, Y. Zhou, K. Amine, S. N. Ehrlich, H. Li, K. W. Nam and X. Q. Yang, Adv. Energy Mater., 2014, 4, 1300950. 